\title{
Percutaneous insertion of peritoneal dialysis catheter is a safe and effective technique irrespective of $\mathrm{BMI}$
}

Dayang Xie ${ }^{\dagger}$, Jianhui Zhou* ${ }^{*}$, Xueying Cao, Qingtao Zhang, Yanli Sun, Li Tang, Jing Huang, Juanli Zheng, Li Lin, Zhenzhen Li, Guangyan Cai and Xiangmei Chen

\begin{abstract}
Background: A large body mass index (BMI) has been considered as a relative contraindication for percutaneous catheter insertion, although this technique has many advantages. Up to now, there are few studies on peritoneal catheter placement and obesity. The aim of this study was to determine whether patients with large BMI can also choose the percutaneous technique for peritoneal dialysis catheter insertion.
\end{abstract}

Methods: One hundred eighty seven consecutive patients underwent peritoneal catheter insertions in the Chinese PLA General Hospital between January 1, 2015 and December 31, 2016, with 178 eligible cases being included in the analysis. Two groups were created based on the catheter insertion techniques, the percutaneous group (group P) and the surgical group (group S). Subgroups were created according to BMI $>28$ or $\leq 28$. The outcomes included catheter related complications and catheter survival.

Results: Total infectious complication rates were significantly lower in group P than in group S. There were no significant differences in peritonitis rate between group $P$ and group $S(1.20 \%$ vs. $3.16 \%$ with $P=0.71$ in early stage, and $4.82 \%$ vs. $11.58 \%$ with $P=0.11$ in late stage). All other measured complications were similar between the two groups. Though the one-year infection-free catheter survival in group P was 7.5\% higher than group $\mathrm{S}$, the difference was not significant. The one-year dysfunction-free catheter survival, one-year dysfunction-and-infectionfree catheter survival, and overall catheter survival were similar between the two groups. Subgroup analyses showed a superior one-year infection-free catheter survival of percutaneous technique in patients with BMI $>28$, which was confirmed by Kaplan-Meier analysis.

Conclusions: Despite the challenges that may be encountered with patients who have a large BMI, the percutaneous technique seems to be a safe and effective approach to placing a peritoneal dialysis catheter.

Keywords: Peritoneal dialysis catheter insertion, Percutaneous, Complication, Survival, BMI

\footnotetext{
*Correspondence: zhou_joseph@yahoo.com; xmchen301@126.com

${ }^{\dagger}$ Dayang Xie and Jianhui Zhou contributed equally to this work.

Department of Nephrology, the First Medical Centre, Chinese PLA General

Hospital, Chinese PLA Institute of Nephrology, State Key Laboratory of Kidney

Diseases (2011DAV00088), National Clinical Research Center for Kidney

Diseases, Fuxing Road 28, Beijing 100853, People's Republic of China
}

(C) The Author(s). 2020 Open Access This article is licensed under a Creative Commons Attribution 4.0 International License, which permits use, sharing, adaptation, distribution and reproduction in any medium or format, as long as you give appropriate credit to the original author(s) and the source, provide a link to the Creative Commons licence, and indicate if changes were made. The images or other third party material in this article are included in the article's Creative Commons licence, unless indicated otherwise in a credit line to the material. If material is not included in the article's Creative Commons licence and your intended use is not permitted by statutory regulation or exceeds the permitted use, you will need to obtain permission directly from the copyright holder. To view a copy of this licence, visit http://creativecommons.org/licenses/by/4.0/ The Creative Commons Public Domain Dedication waiver (http://creativecommons.org/publicdomain/zero/1.0/) applies to the data made available in this article, unless otherwise stated in a credit line to the data. 


\section{Background}

Peritoneal dialysis (PD) is one of the major renal replacement therapies for end stage renal disease, which compared to hemodialysis has the added benefits of preserving residual renal function, offering a better quality of life, less expensive, minimal infrastructure required, hemodynamic stability and similar survival [1-5]. Peritoneal dialysis is a preferred modality for patients expecting to receive a transplant [6], it can be used for urgent-start dialysis [7], and possible earlier recovery of kidney function in acute kidney injury [8].

One of the keys to successful PD and avoidance of urgent hemodialysis is creating access to timely insertion of a well-functioning peritoneal dialysis catheter [9-11]. Currently, there are several techniques available for PD catheter placement which include surgical, laparoscopic and percutaneous [10].. Each technique has its own advantages and shortcomings. Compared with other methods, percutaneous catheter insertion is a simple and shorter procedure with low complication rate. It requires minimal training to perform and can offer early recovery from the procedure. Thus, percutaneous insertion of PD catheters should theoretically be a preferred choice of technique by primary nephrologists. However, a large BMI has been considered a relative contraindication to percutaneous insertion [12-16], which has limited its use in obese patients. Currently, the number of people suffering from overweight and obesity continues to rise, but there are few studies on peritoneal catheter placement techniques and obesity. The aim of this study was to compare the outcomes of percutaneous and surgically placed PD catheters on patients with a large BMI (>28), with the primary outcome being the overall catheter survival and secondary outcomes being non-infectious complication rates, infectious complication rates, catheter dysfunction-free survival, catheter infection-free survival, catheter dysfunctionand-infection-free survival.

\section{Methods}

\section{Study design}

We retrospectively examined collected data on 187 consecutive patients who had undergone surgical technique and percutaneous technique peritoneal catheter insertions in the Chinese PLA General Hospital between January 1, 2015 and December 31, 2016. Inclusion criteria: 1 . age $\geq 18$ years; 2 . the catheter style was a straight Tenckhoff. Exclusion criteria: the medical record was incomplete, such as lack of BMI value, complications or survival. A total of 178 eligible cases were included in the analysis. Two groups were created based on the catheter insertion techniques: percutaneous group (group P, $n=83$ ) and surgical group (group $\mathrm{S}, n=95$ ). Subgroups were created according to BMI. Subgroup A consisted of 22 obese patients with $\mathrm{BMI}>28,12$ percutaneous and 10 surgical. Subgroup B consisted of 156 patients with a $\mathrm{BMI} \leq 28,71$ percutaneous and 85 surgical (Fig. 1). The outcomes of percutaneous and surgical techniques were compared and the effect of BMI was determined.

\section{Patient characteristics and data sources}

All patients had a clear clinical diagnosis of underlying renal disease and required renal replacement therapy prior to a PD catheter insertion. The catheters were placed percutaneously or surgically by three experienced nephrologists from the PD center of Chinese PLA General Hospital who used the same operation approach. Catheter insertions were performed according to the published protocols [17-19]. Percutaneous insertions were performed at the bedside within $24 \mathrm{~h}$ to $48 \mathrm{~h}$ after admission. Surgical insertions were performed in a sterile operating room, on average, five to 7 days after admission due to limited operating room availability. The choice of catheter insertion method was not randomized but rather decided by the preference of the physician and patient. The percutaneous technique was commonly chosen for patients who were elderly, immobile, medically unstable or requiring urgent dialysis. All percutaneous and most surgical insertions were performed under local anesthesia. Prophylactic antibiotics (first or second generation cephalosporin) and phenobarbital sodium intramuscular were routinely given prior to the procedure. The data source was the medical records of the regularly scheduled follow-up registration system of our PD program. Patient follow-up and medical records were written by our PD doctors and nurses.

\section{Outcomes and definitions}

The measured outcomes included: non-infectious complication rates, infectious complication rates, catheter dysfunction-free survival, catheter infection-free survival, catheter dysfunction-and-infection-free survival, and overall catheter survival. Patient survival was not included as an outcome as the 5 deaths were not related to catheter insertion technique. Instead, patient death was a censoring condition of catheter survival. We defined complications occurring within 30 days (non-infectious) or within 2 weeks (infectious) after catheter insertion as early complications, otherwise described as late $[19,20]$. The non-infectious complications consisted of mechanical catheter dysfunction, leakage, hernia development, bleeding, visceral injury and insertion failure. Mechanical catheter dysfunction was defined as inflow/ outflow obstruction, catheter tip migration, omental wrap, and blood or fibrin clot requiring revisionary surgery or catheter removal. The infectious complications 


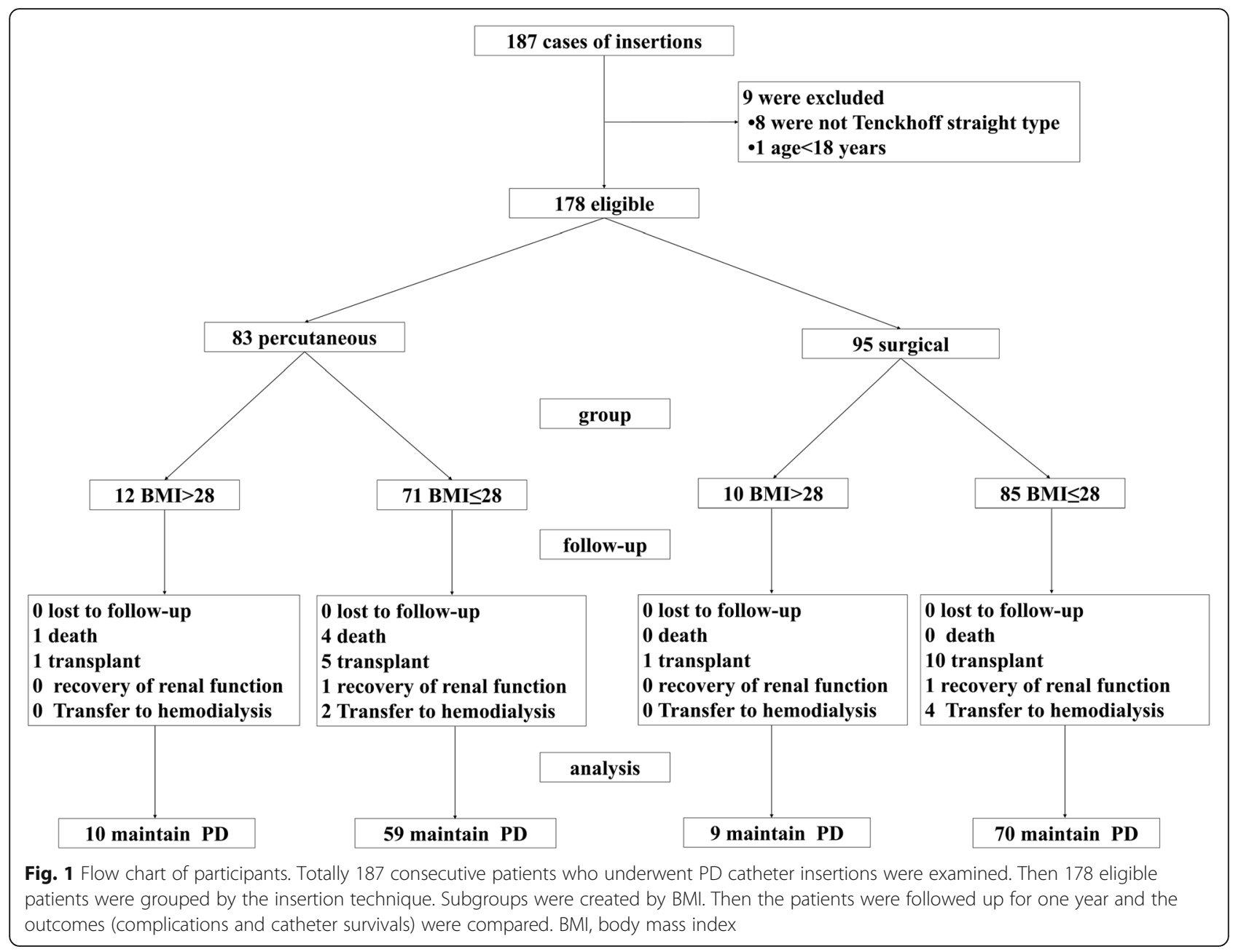

consisted of peritonitis, catheter related infections (exitsite and tunnel infection). The definition of peritonitis, exit-site and tunnel infection complied with the ISPD guideline [21]. Catheter dysfunction-free survival was defined as total length of time from catheter insertion to revisionary surgery or removal due to mechanical dysfunction only. The case was censored if lost to followup, death, catheter removal for other reasons, i.e., peritonitis, catheter related infections, ultrafiltration failure, renal transplant, renal recovery, or patient's preference for hemodialysis. Catheter infection-free survival was defined as total length of time from catheter insertion to peritonitis or catheter related infections. Catheter dysfunction-and-infection-free survival was defined as total length of time from catheter insertion either to surgery revision or removal due to mechanical dysfunction, or infectious complications. The overall catheter survival was defined as total length of time from catheter insertion to removal. The cases lost to follow-up, death, renal transplanted, or renal recovery were censored. Each patient was followed up for 1 year from the day of catheter insertion.

\section{Statistical analysis}

SPSS 17.0 was used for statistical analysis, continuous variables were represented by mean \pm standard deviation, non-continuous variables were expressed as percentage. Comparisons between groups were conducted by independent $\mathrm{t}$-test or chi-square test, the subgroup analysis was conducted by stratified chi-square test, and catheter survival was assessed using the Kaplan-Meier method with log-rank test. Statistical significance was established at 0.05 .

\section{Results}

\section{Characteristics of participants}

The cohort comprised 187 consecutive PD catheter insertions from January 1, 2015 to December 31, 2016, while 178 eligible cases were included in the analysis. The baseline characteristics are shown in Table 1. The mean age of group $\mathrm{P}$ was significantly higher than that of group S ( $48.07 \pm 16.84$ years vs. $43.22 \pm 13.13$ years, $P=0.04$ ). There were no significant differences in mean weight or mean BMI. Sex ratio of group P was similar to that of group S, $62.65 \%$ (52 cases) and $66.32 \%$ (63 cases) 
Table 1 Baseline patient characteristics at PD catheter insertion

\begin{tabular}{|c|c|c|c|}
\hline Characteristics & $\begin{array}{l}\text { Percutaneous } \\
(n=83)\end{array}$ & $\begin{array}{l}\text { Surgical } \\
(n=95)\end{array}$ & $P$-value \\
\hline \multicolumn{4}{|l|}{ Sex [n (\%)] } \\
\hline Male & $52(62.65)$ & $63(66.32)$ & \multirow[t]{2}{*}{0.61} \\
\hline Female & $31(37.35)$ & $32(33.68)$ & \\
\hline Age (years) & $48.07 \pm 16.84$ & $43.22 \pm 13.13$ & 0.04 \\
\hline$\geq 65$ years $[n(\%)]$ & $28(33.73)$ & $4(4.21)$ & $<0.001$ \\
\hline Weight (kg) & $65.97 \pm 15.34$ & $66.87 \pm 13.34$ & 0.67 \\
\hline BMI (kg/m2) & $23.44 \pm 4.02$ & $23.48 \pm 3.84$ & 0.95 \\
\hline$>28[\mathrm{n}(\%)]$ & $12(14.46)$ & $10(10.53)$ & \multirow[t]{2}{*}{0.43} \\
\hline$\leq 28[\mathrm{n}(\%)]$ & $71(85.54)$ & $85(89.47)$ & \\
\hline Serum albumin $(\mathrm{g} / \mathrm{L})$ & $36.20 \pm 4.40$ & $37.76 \pm 4.24$ & 0.02 \\
\hline Serum creatinine $(\mu \mathrm{mol} / \mathrm{L})$ & $886.66 \pm 324.41$ & $791.37 \pm 230.15$ & 0.03 \\
\hline eGFR (CKD-EPI) [mL/(min.1.73 m2)] & $5.69 \pm 2.08$ & $6.47 \pm 2.01$ & 0.01 \\
\hline Acute kidney injury [n (\%)] & $1(1.20)$ & $1(1.05)$ & \\
\hline Chronic kidney diseases [n (\%)] & $82(98.80)$ & $94(98.95)$ & 0.92 \\
\hline \multicolumn{4}{|l|}{ Comorbidity [n (\%)] } \\
\hline Hypertension & 79 (95.18) & $83(87.37)$ & 0.07 \\
\hline Diabetes & $13(15.66)$ & $13(13.68)$ & 0.71 \\
\hline Coronary artery disease & $9(10.84)$ & $5(5.26)$ & 0.17 \\
\hline Cerebrovascular disease & $7(8.43)$ & $6(6.32)$ & 0.59 \\
\hline Carotid atherosclerosis & $60(72.29)$ & $36(37.89)$ & $<0.001$ \\
\hline Respiratory disease & $11(13.25)$ & 0 & \multirow[t]{7}{*}{$<0.001$} \\
\hline Chronic bronchitis & $4(4.82)$ & 0 & \\
\hline Old pulmonary tuberculosis & $1(1.20)$ & 0 & \\
\hline Bronchial asthma & $3(3.61)$ & 0 & \\
\hline Bronchiectasis & $1(1.20)$ & 0 & \\
\hline Interstitial lung disease & $1(1.20)$ & 0 & \\
\hline Sleep apnea hypopnea syndrome & $1(1.20)$ & 0 & \\
\hline Planned catheter insertion [n (\%)] & 60 (72.29) & $95(100)$ & $<0.001$ \\
\hline
\end{tabular}

Continuous variables are presented as mean \pm SD, while non-continuous variables are presented as number (percentage). Weight was examined under standard conditions, i.e., after urinating and defecating with empty peritoneal cavity. Hypertension was judged by $140 / 90 \mathrm{mmHg}$ or $150 / 90 \mathrm{mmHg}$ (age $\geq 60$ ). Carotid atherosclerosis was determined by ultrasound. BMI Body mass index

of male, respectively, $P=0.61$. There was a higher incidence of carotid atherosclerosis in group $\mathrm{P}$ than in group S, $72.29 \%$ (60 cases) vs. $37.89 \%$ (36 cases), $P<$ 0.001 . Respiratory disease was more commonly observed in group P $(13.25 \%, 11$ cases) than in group S (none), $P<0.001$. There was no significant difference in other comorbidities, such as diabetes, hypertension, coronary heart disease or cerebrovascular disease.

\section{Non-infectious complications}

Non-infectious complications of the two groups are shown in Table 2. In the present study, none of the patients had insertion failure, visceral injury, leakage, severe bleeding, or hernia development during the early period. Late stage hernia development was observed more commonly in group $\mathrm{S}(4.21 \%, 4$ cases) than in group $\mathrm{P}$ (none), though of no statistical significance. Early mechanical catheter dysfunction rates were similar between the two groups (9.64 and $9.47 \%$ for group $\mathrm{P}$ and $S$ respectively, $P=0.97$ ). Late mechanical dysfunction rates were as well similar $(2.41$ and $3.16 \%$ for group $\mathrm{P}$ and $\mathrm{S}$ respectively, $P=1.00$ ). Total non-infectious complication rates were similar between the two groups (12.05 and $16.84 \%$ for group $\mathrm{P}$ and $\mathrm{S}$ respectively, $P=$ 0.37). The results of subgroup analysis (shown in Table 3) were similar to the above.

\section{Infectious complications}

Infectious complications of the two groups are shown in Table 2. Early stage catheter related infections were not 
Table 2 Complications over one year of follow-up

\begin{tabular}{|c|c|c|c|}
\hline Complications & Percutaneous $(n=83)$ & Surgical $(n=95)$ & $P$-value \\
\hline \multicolumn{4}{|l|}{ Non-infectious complications } \\
\hline \multicolumn{4}{|l|}{ Early [n (\%)] } \\
\hline Mechanical catheter dysfunction & $8(9.64)$ & $9(9.47)$ & 0.97 \\
\hline Dialysate leakage & 0 & 0 & - \\
\hline Hernia & 0 & 0 & - \\
\hline Bleeding & 0 & 0 & - \\
\hline Visceral injury & 0 & 0 & - \\
\hline Insertion failure & 0 & 0 & - \\
\hline \multicolumn{4}{|l|}{ Late [n (\%)] } \\
\hline Mechanical catheter dysfunction & $2(2.41)$ & $3(3.16)$ & 1.00 \\
\hline Dialysate leakage & 0 & 0 & - \\
\hline Hernia & 0 & $4(4.21)$ & 0.17 \\
\hline Bleeding & 0 & 0 & - \\
\hline Total [n (\%)] & $10(12.05)$ & $16(16.84)$ & 0.37 \\
\hline \multicolumn{4}{|l|}{ Infectious complications } \\
\hline \multicolumn{4}{|l|}{ Early [n (\%)] } \\
\hline Peritonitis & $1(1.20)$ & $3(3.16)$ & 0.71 \\
\hline Catheter related infections & 0 & 0 & - \\
\hline \multicolumn{4}{|l|}{ Late [n (\%)] } \\
\hline Peritonitis & $4(4.82)$ & $11(11.58)$ & 0.11 \\
\hline Catheter related infections & 0 & $1(1.05)$ & 1.00 \\
\hline Total [n (\%)] & $5(6.02)$ & 15 (15.79) & 0.04 \\
\hline
\end{tabular}

Variables are presented as number and percentage (if number is not 0). The upper half of the table is non-infectious complications, and the lower half is infectious complications. Both non-infectious and infectious complications are divided into three parts, i.e., early stage, late stage and total. Early was defined as complications occurred within 30 days after catheter insertion (for non-infectious), or 2 weeks after insertion (for infectious). Bleeding means only severe conditions when demanding transfusion or surgical hemostasis. Catheter related infection consists of exit site and tunnel infections

observed in group P or S. Late stage catheter related infections were similar between group P (none) and group $\mathrm{S}(1.05 \%), P=1.00$. There were no significant differences in peritonitis rate between the two groups $(1.20 \%$ vs. $3.16 \%$ with $P=0.71$ in early stage, and $4.82 \%$ vs. $11.58 \%$ with $P=0.11$ in late stage). Total infectious complication rate was lower in group $\mathrm{P}(6.02 \%)$ than in group $\mathrm{S}$ (15.79\%), $P=0.04$.

The results of subgroup analysis are shown in Table 3 . Between different subgroups, only the total infectious complication distribution was significantly different $(P=$ 0.02 ). This difference was driven mainly by subgroup $A$ in which the total infectious complication rate of group P (4.55\%) was lower than that of group S (22.73\%). Both the early and the late infectious complication distributions showed no difference between subgroup A and B.

\section{One-year catheter survival}

The one-year dysfunction-free catheter survivals were similar between the two groups, $71.08 \%$ (59 cases) and $74.74 \%$ (71 cases) for group $P$ and $S$, respectively, $P=0.58$. The one-year infection-free catheter survivals were also similar between the two groups, $75.90 \%$ (63 cases) and $68.42 \%$ (65 cases) for group $P$ and $S$, respectively, $P=0.27$. Similarly, the one-year dysfunction-and-infection-free catheter survivals showed no significance between the two groups, $65.06 \%$ (54 cases) and 63.16\% (60 cases) for group $\mathrm{P}$ and $\mathrm{S}$ respectively, $P=0.79$. The overall catheter survival was also similar between the two groups, 81.93\% (68 cases) and $81.05 \%$ (77 cases) for group $\mathrm{P}$ and $\mathrm{S}$, respectively, $P=0.88$. The one-year infection-free catheter survival demonstrated the largest gap between the two groups (group P $75.90 \%$ vs. group S 68.42\%), though not of statistical significance. However, a significant difference appeared in Kaplan-Meier analysis for one-year infectionfree catheter survival between group P and S (by log-rank test $P=0.04$, Fig. 2).

The results of subgroup analysis are shown in Table 4. Between different subgroups, the one-year infection-free catheter survival distribution was significantly different. Further, we discovered that in subgroup A the survival of group P (40.91\%) was higher than that of group S (22.73\%). The one-year dysfunction-free catheter survival, one-year dysfunction-and-infection-free catheter 
Table 3 Subgroup analysis for the complications by BMI (Percutaneous versus Surgical)

\begin{tabular}{|c|c|c|c|c|c|c|}
\hline \multirow[t]{2}{*}{ Complications } & \multicolumn{2}{|c|}{ Percutaneous $(n=83)$} & \multicolumn{2}{|c|}{ Surgical $(n=95)$} & \multirow[t]{2}{*}{$\mathrm{OR}_{\mathrm{MH}}(95 \% \mathrm{Cl})$} & \multirow[t]{2}{*}{ P-valu } \\
\hline & $\begin{array}{l}\mathrm{BMI}>28 \\
(n=12)\end{array}$ & $\begin{array}{l}\mathrm{BMI} \leq 28 \\
(n=71)\end{array}$ & $\begin{array}{l}\mathrm{BMI}>28 \\
(n=10)\end{array}$ & $\begin{array}{l}\mathrm{BMI} \leq 28 \\
(n=85)\end{array}$ & & \\
\hline \multicolumn{7}{|l|}{ Non-infectious complications } \\
\hline \multicolumn{7}{|l|}{ Early [n (\%)] } \\
\hline Mechanical PD catheter dysfunction & 0 & $8(5.13)$ & $1(4.55)$ & $8(5.13)$ & 1.05 (0.39 to 2.83) & 0.93 \\
\hline Dialysate leak & 0 & 0 & 0 & 0 & - & - \\
\hline Hernia & 0 & 0 & 0 & 0 & - & - \\
\hline Bleeding & 0 & 0 & 0 & 0 & - & - \\
\hline Visceral injury & 0 & 0 & 0 & 0 & - & - \\
\hline Insertion failure & 0 & 0 & 0 & 0 & - & - \\
\hline \multicolumn{7}{|l|}{ Late $[\mathrm{n}(\%)]$} \\
\hline Mechanical PD catheter dysfunction & $1(4.55)$ & $1(0.64)$ & 0 & $3(1.92)$ & 0.73 (0.12 to 4.62$)$ & 0.74 \\
\hline Dialysate leak & 0 & 0 & 0 & 0 & - & - \\
\hline Hernia & 0 & 0 & 0 & $4(2.56)$ & 0.00 & 0.06 \\
\hline Bleeding & 0 & 0 & 0 & 0 & - & - \\
\hline Total [n (\%)] & $1(4.55)$ & $9(5.77)$ & $1(4.55)$ & $15(9.62)$ & 0.69 (0.29 to 1.62$)$ & 0.39 \\
\hline \multicolumn{7}{|l|}{ Infectious complications } \\
\hline \multicolumn{7}{|l|}{ Early (n) } \\
\hline Peritonitis & 0 & $1(0.64)$ & $1(4.55)$ & $2(1.28)$ & 0.37 (0.04 to 3.45) & 0.35 \\
\hline Catheter related infections & 0 & 0 & 0 & 0 & - & - \\
\hline \multicolumn{7}{|l|}{ Late [n (\%)] } \\
\hline Peritonitis & $1(4.55)$ & $3(1.92)$ & $3(13.64)$ & $8(5.13)$ & $0.36(0.11$ to 1.19$)$ & 0.08 \\
\hline Catheter related infections & 0 & 0 & $1(4.55)$ & 0 & 0.00 & 0.26 \\
\hline Total (n) & $1(4.55)$ & $4(2.56)$ & $5(22.73)$ & $10(6.41)$ & $0.32(0.11$ to 0.91$)$ & 0.02 \\
\hline
\end{tabular}

Variables are presented as number and percentage (if number is not 0). The percentage is the proportion of complications in the relevant subgroup. Subgroup analysis was performed by stratified chi-square test. The upper half of the table is non-infectious complications, and the lower half is infectious complications. Both non-infectious and infectious complications are divided into three parts, i.e., early stage, late stage and total. Early was defined as complications occurred within 30 days after catheter insertion (for non-infectious), or 2 weeks after insertion (for infectious). Bleeding means only severe conditions when demanding transfusion or surgical hemostasis. Catheter related infection consists of exit site and tunnel infections. Subgroup A: data in the two columns of BMI > 28, subgroup $\mathrm{B}$ : data in the two columns of $\mathrm{BMI} \leq 28$. BMI Body mass index

survival, and overall catheter survival distributions were similar between all subgroups. Kaplan-Meier survival analysis confirmed that the one-year infection-free catheter survival of group $\mathrm{P}$ was significantly higher than that of group $\mathrm{S}$ in subgroup A (by $\log$-rank test $P=0.03$, Fig. 3 ).

\section{Discussion}

In the present study, total infectious complications of percutaneous insertion were significantly fewer than those of surgical insertion. Kaplan-Meier analysis demonstrated a significant higher one-year infection-free catheter survival in group $\mathrm{P}(93.3 \%)$ than in group $\mathrm{S}$ (83.3\%). It should also be noted that despite the fact that group P was older with more co-morbidities, they had a lower rate of infectious complication and longer catheter survival.

In recent years, peritoneal dialysis has been widely used because of mortality benefits, improved quality of life, preserved residual renal function, lower cost, minimal infrastructure required and hemodynamic stability. PD may be a good option under certain circumstances such as hemodynamic instability, limited vascular access, active bleeding or bleeding tendencies. PD can also be used for acute kidney injury, heart failure, elderly patients, and urgent-start dialysis [7, 22-30]. As stated previously one of the key steps to having a successful PD program is having access to timely PD catheter placement [31]. Currently, there are several techniques available for PD catheter placement which include surgical, laparoscopic and percutaneous. Compared with other methods, percutaneous insertion is a simple procedure, with the benefits of quick recovery, earlier ambulation, and less delay in catheter placement $[16,32,33]$. In addition, because of avoiding a large peritoneal incision and the need for suturing, the percutaneous insertion can save much more time during the procedure $[34,35]$. Some studies have reported that the mechanical complication rate of percutaneous insertion 


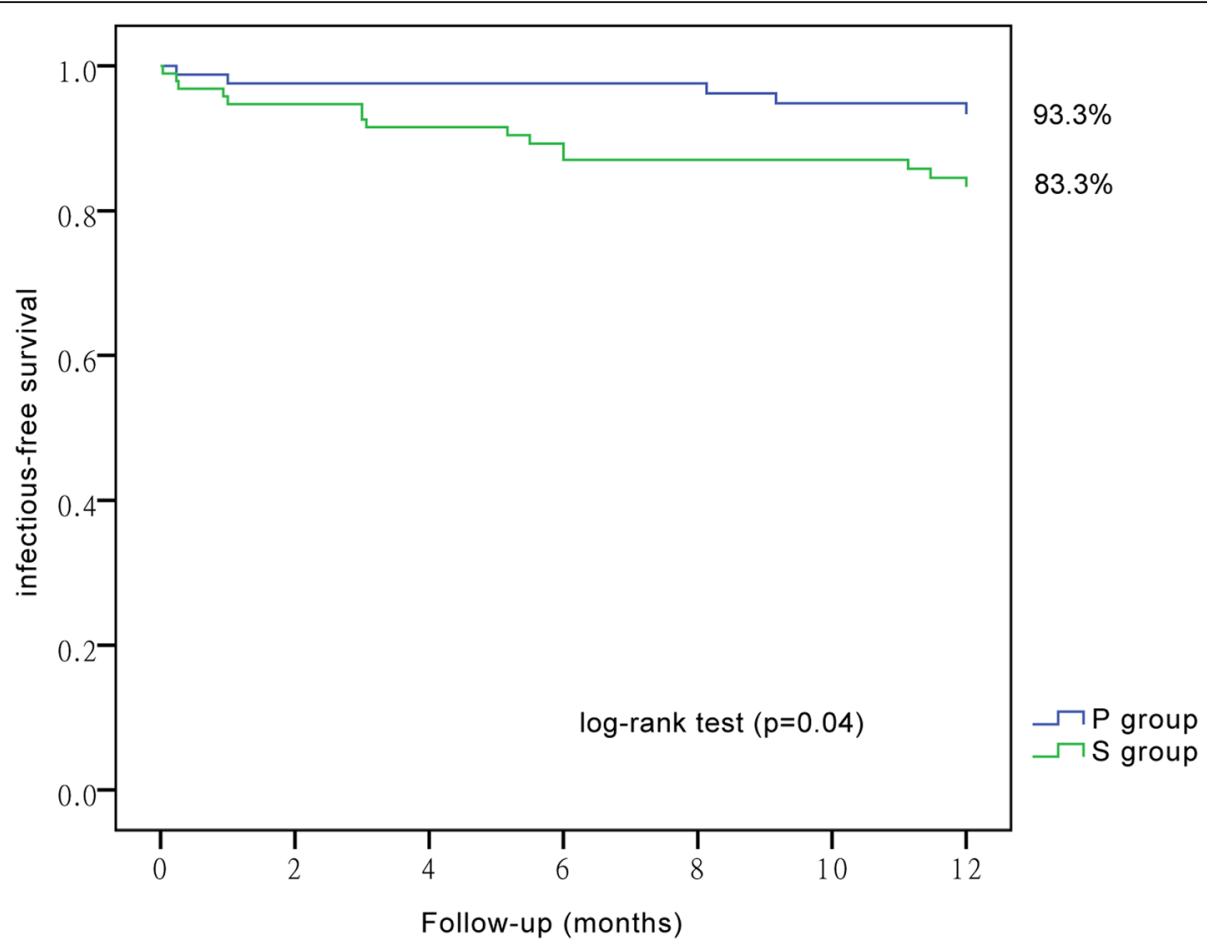

Fig. 2 One-year infection-free catheter survival was better in patients undertaking percutaneous insertion. Patients were divided into two groups by insertion technique, i.e., percutaneous group (group P) and surgical group (group S). Follow-up period was one year. Then infection-free catheter survival was plotted by Kaplan-Meier curves. Log-rank test was performed to examine the significance

was similar to that of surgical and laparoscopic $[10,15$, $33,36]$, the infectious complication rate was lower [10, 36, 37], and survival was better [33]. Similar conclusions have been drawn in this study. The major concern with the percutaneous placement is that it is a "blind" technique with the risk of inadvertent puncture of the abdominal viscera and possible bleeding. However, the very low frequency of perforation reported in previous studies $(0-1.3 \%)$ argued against the magnitude of this complication [38-42]. In the present study, none of the patients experienced a visceral injury or severe bleeding, and fewer patients in the percutaneous group had infectious complications. One of the most important points of this study was the fact that all of the percutaneous insertions were completed by nephrologists, which can reduce unnecessary procedures such as temporary hemodialysis catheters, and improve PD utilization by avoiding delays in catheter placement due to limited operating room slates and losing appropriate PD patients to hemodialysis $[9,11,33,43]$. In addition, it has been shown that nephrologists taking ownership of catheter placement improves the success and growth of peritoneal dialysis programs [44].

Although there are many advantages using the percutaneous technique, most studies describe a $\mathrm{BMI}>28$ as a relative contraindication [12-16]. McDonald et al. [45]

Table 4 Subgroup analysis for one-year catheter survival by BMI (Percutaneous versus Surgical)

\begin{tabular}{|c|c|c|c|c|c|c|}
\hline \multirow[t]{2}{*}{ one-year catheter survival } & \multicolumn{2}{|c|}{ Percutaneous $(n=83)$} & \multicolumn{2}{|c|}{ Surgical $(n=95)$} & \multirow[t]{2}{*}{$\mathrm{OR}_{\mathrm{MH}}(95 \% \mathrm{Cl})$} & \multirow[t]{2}{*}{$P$-value } \\
\hline & $\begin{array}{l}\mathrm{BMI}>28 \\
(n=12)\end{array}$ & $\begin{array}{l}\mathrm{BMI} \leq 28 \\
(n=71)\end{array}$ & $\begin{array}{l}\mathrm{BMI}>28 \\
(n=10)\end{array}$ & $\begin{array}{l}\mathrm{BMI} \leq 28 \\
(n=85)\end{array}$ & & \\
\hline Dysfunction-free [n (\%)] & $9(40.91)$ & $50(32.05)$ & $9(40.91)$ & $62(39.74)$ & 0.99 (0.40 to 2.45$)$ & 0.98 \\
\hline Infection-free [n (\%)] & $9(40.91)$ & $54(34.62)$ & $5(22.73)$ & $60(38.46)$ & 3.04 (1.04 to 8.87$)$ & 0.03 \\
\hline Dysfunction-and-infection-free [n (\%)] & $8(36.36)$ & $46(29.49)$ & $5(22.73)$ & $55(35.26)$ & 1.52 (0.73 to 3.17$)$ & 0.26 \\
\hline Overall catheter survival [n (\%)] & $10(45.45)$ & $58(37.18)$ & $9(40.91)$ & $68(43.59)$ & $1.71(0.41$ to 7.13$)$ & 0.46 \\
\hline
\end{tabular}

Variables are presented as number and percentage. The percentage is the proportion of survival cases in the relevant subgroup. Subgroup analysis was performed by stratified chi-square test. Catheter dysfunction-free survival was defined as total length of time from catheter insertion to revisionary surgery or removal due to mechanical dysfunction only. Catheter infection-free survival was defined as total length of time from catheter insertion to peritonitis or catheter related infections. Catheter dysfunction-and-infection-free survival was defined as total length of time from catheter insertion either to revisionary surgery or removal due to mechanical dysfunction, or to infectious complications (peritonitis, or catheter related infections). The overall catheter survival was defined as total length of time from catheter insertion to removal. Subgroup A: data in the two columns of $B M I>28$, subgroup $B$ : data in the two columns of $B M I \leq 28$. BMI Body mass index 


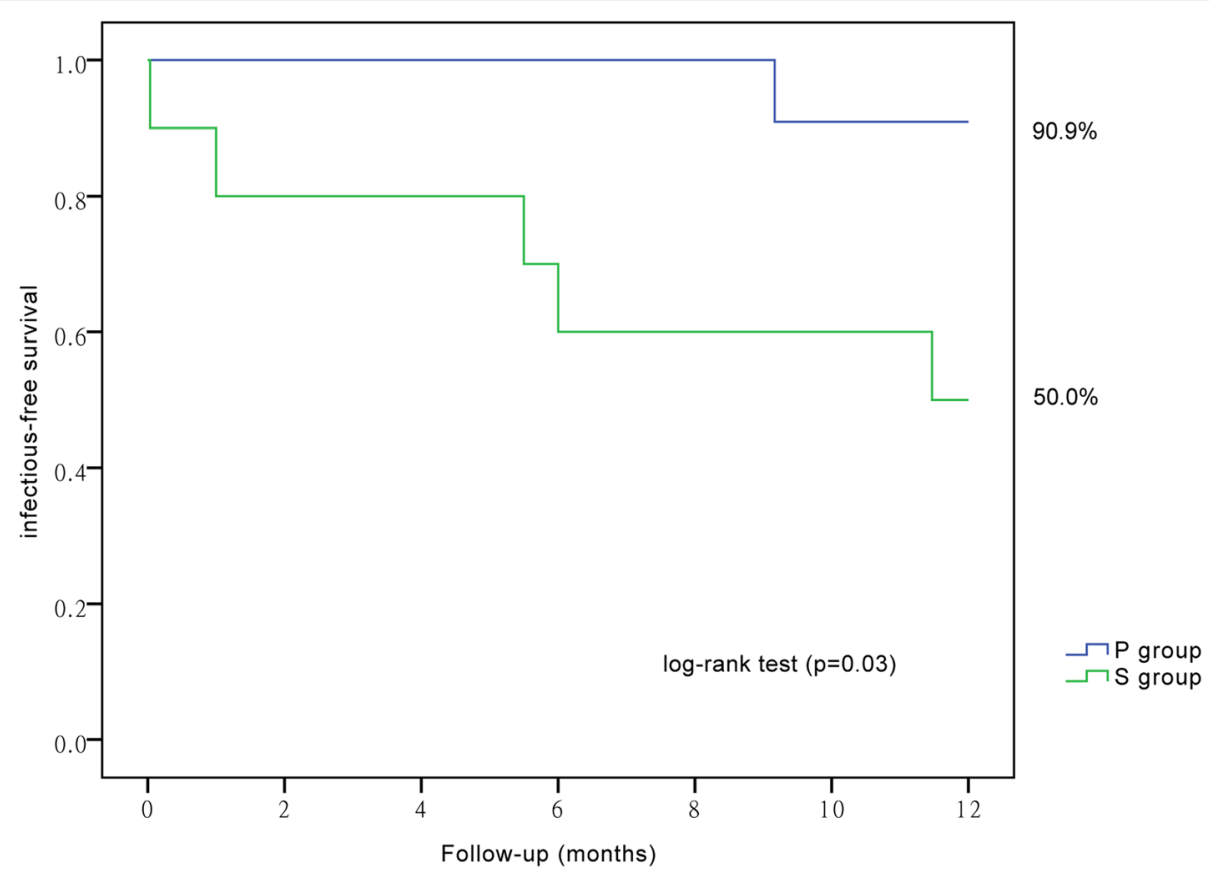

Fig. 3 Among patients with a larger BMl, percutaneous technique presented a better one-year infection-free catheter survival than surgical technique. Patients were grouped by insertion technique, i.e., percutaneous group (group P) and surgical group (group S). Then subgroups were created according to patients' BMI. This figure shows only patients in subgroup A (BMI > 28, 12 percutaneous and 10 surgical). Follow-up period was one year. Then Kaplan-Meier analysis with log-rank test was performed for infection-free catheter survival. BMI, body mass index

believed that obesity was a negative influencing factor of PD technique survival. Recently, there have been several studies which have described successful treatment of obese patients using peritoneal dialysis [46-49]. However, there is minimal information on PD catheter placement in this population. Singh et al. [50] evaluated a cohort of 315 patients and found that BMI was not an influencing factor of PD catheter survival, but all catheter studied were inserted by surgical placement. Krezalek et al. [51] conducted a cohort study using BMI as influencing factor, and found that obesity did not increase complications or shorten dysfunction-free catheter survival but only laparoscopic and open surgical catheter placement were included. Shanmugalingam et al. [52] utilized ultrasound assessment for selection of patients for percutaneous insertion of PD catheters, but obese patients were excluded. In fact, there was little knowledge about the outcomes of percutaneous insertion and overweight patients until now. The results of our study demonstrated that the outcomes of patients with a large BMI are similar to or better than their counterparts. This offers a possibility for the application of percutaneous catheter insertion in patients with BMI $>28$.

Due to the short time of observation, some late complications might not be fully manifested, so the longterm outcomes such as death, were not included in the analysis. Kaplan-Meier analysis might overestimate the event rate due to the presence of competing risks, and yield biased results. This is a retrospective study, the choice of catheter insertion method was not randomized. The patients in group P were older and with more comorbidities, but they had a lower rate of infectious complication and longer catheter survival. So this is a better explanation of the advantages of group P. However, a randomly designed, relatively large prospective cohort would be required to directly confirm the results obtained in the present study.

\section{Conclusions}

Percutaneous insertion of peritoneal dialysis catheters appears to be a safe and effective technique for catheter placement, and it may be a good choice to the PD catheter placement for patients with a large BMI. However, a larger series of studies would be needed to verify the safety and efficacy of the technique.

\section{Abbreviations}

BMl: Body mass index; PD: Peritoneal dialysis

\section{Acknowledgments}

The authors would like to thank Professor Sean Armstrong for the valuable opinions and the detailed revisions for the manuscript.

\section{Authors' contributions}

DYX and JHZ drafted the paper, participated in the design of the study, and took the main part in catheter insertion procedures, these two authors contributed equally to this paper. XYC assisted in protocol revision and participated in catheter insertions. QTZ was responsible for the clinical 
protocol and participated in the study design. YLS helped to get some important outcome data. $L T, J H, J L Z, L L$ and $Z Z L$ assisted in gathering the data. GYC and XMC participated in study design and revision of the protocol. XMC took charge of organizing the study group and guiding the study process. JHZ was responsible for detailed arrangements. All authors had approved the final manuscript.

\section{Funding}

This work was performed in the State Key Laboratory of Kidney Diseases (2011DAV00088), and supported by the Foundation for National Clinical Research Center (2015BAl12B06), the National Key Research and Development Project (2016YFC1103004), the Four-hundred Project of Chinese PLA General Hospital (MJ201407), the Chinese Academy of Engineering Consulting Research Project (2017-XZ-08) and National Key R\&D Program of China (2018YFC0114503). The opinions, results and conclusions reported in this paper were those of the authors and were independent from the funding sources.

\section{Availability of data and materials}

The datasets analysed during the current study are available from the corresponding author on reasonable request.

\section{Ethics approval and consent to participate}

This research is an observational study. All protocols were approved by the Medicine Ethics Committee of Chinese PLA General Hospital (No. S2019-037-01)

\section{Consent for publication}

Not applicable.

\section{Competing interests}

The authors declare that they have no competing interests. The co-author Xiangmei Chen is the editorial board member of BMC Nephrology.

Received: 27 May 2019 Accepted: 11 May 2020

Published online: 25 May 2020

\section{References}

1. Waldum-Grevbo B, Leivestad T, Reisæter AV, Os I. Impact of initial dialysis modality on mortality: a propensity-matched study. BMC Nephrol. 2015;16: 179.

2. Lu R, Estremadoyro C, Chen X, Zhu M, Ribeiro LC, Yan Y, et al. Hemodialysis versus peritoneal dialysis: an observational study in two international centers. Int J Artif Organs. 2017;8:0.

3. Tokgoz B. Clinical advantages of peritoneal dialysis. Perit Dial Int. 2009;29: S59-61.

4. Heaf JG, Wehberg S. Relative survival of peritoneal dialysis and haemodialysis patients: effect of cohort and mode of dialysis initiation. PLoS One. 2014;9:e90119.

5. Karopadi AN, Mason G, Rettore E, Ronco C. Cost of peritoneal dialysis and haemodialysis across the world. Nephrol Dial Transplant. 2013;28:2553-69.

6. Joachim E, Gardezi Al, Chan MR, Shin JI, Astor BC, Waheed S. Association of pre-Transplant Dialysis Modality and Post-Transplant Outcomes: a metaanalysis. Perit Dial Int. 2017;37:259-65.

7. Ghaffari A. Urgent-start peritoneal dialysis: a quality improvement report. Am J Kidney Dis. 2012;59:400-8.

8. Gabriel DP, Caramori JT, Martim LC, Barretti P, Balbi AL. High volume peritoneal dialysis vs daily hemodialysis: a randomized, controlled trial in patients with acute kidney injury. Kidney Int Suppl. 2008:S87-93.

9. Goh BL, Ganeshadeva YM, Chew SE, Dalimi MS. Does peritoneal dialysis catheter insertion by interventional nephrologists enhance peritoneal dialysis penetration? Semin Dial. 2008;21:561-6.

10. Medani S, Shantier M, Hussein W, Wall C, Mellotte G. A comparative analysis of percutaneous and open surgical techniques for peritoneal catheter placement. Perit Dial Int. 2012;32:628-35.

11. Asif A, Byers P, Gadalean F, Roth D. Peritoneal dialysis underutilization: the impact of an interventional nephrology peritoneal dialysis access program. Semin Dial. 2003;16:266-71.

12. Perakis KE, Stylianou KG, Kyriazis JP, Mavroeidi VN, Katsipi IG, Vardaki EA, et al. Long-term complication rates and survival of peritoneal dialysis catheters: the role of percutaneous versus surgical placement. Semin Dial. 2009;22:569-75.
13. De Boo DW, Mott N, Tregaskis P, Quach T, Menahem S, Walker RG, et al. Percutaneous insertion of peritoneal dialysis catheters using ultrasound and fluoroscopic guidance: a single Centre experience and review of literature. J Med Imaging Radiat Oncol. 2015;59:662-7.

14. Voss D, Hawkins S, Poole G, Marshall M. Radiological versus surgical implantation of first catheter for peritoneal dialysis: a randomized noninferiority trial. Nephrol Dial Transplant. 2012;27:4196-204.

15. Maher E, Wolley MJ, Abbas SA, Hawkins SP, Marshall MR. Fluoroscopic versus laparoscopic implantation of peritoneal dialysis catheters: a retrospective cohort study. J Vasc Interv Radiol. 2014;25:895-903.

16. Henderson S, Brown E, Levy J. Safety and efficacy of percutaneous insertion of peritoneal dialysis catheters under sedation and local anaesthetic. Nephrol Dial Transplant. 2009;24:3499-504.

17. Cheng XM. Peritoneal Dialysis Standard Operating Procedure (SOP). PEOPLE'S MILITARY MEDICAL PRESS. Beijing, China, 2010, 1rd Ed, pp 17-24.

18. Cheng XM. Practical Course in Peritoneal Dialysis. PEOPLE'SMILITARY MEDICAL PRESS. Beijing, China, 2013, 1rd Ed, pp 19-40.

19. Crabtree JH, Shrestha BM, Chow KM, Figueiredo AE, Povlsen JV, Wilkie M, et al. Creating and maintaining optimal peritoneal Dialysis access in the adult patient: 2019 update. Perit Dial Int. 2019;39:414-36.

20. Peppelenbosch A, van Kuijk WH, Bouvy ND, van der Sande FM, Tordoir JH. Peritoneal dialysis catheter placement technique and complications. NDT Plus. 2008;1(Suppl 4):iv23-8.

21. Li PK, Szeto CC, Piraino B, de Arteaga J, Fan S, Figueiredo AE, et al. ISPD peritonitis recommendations: 2016 update on prevention and treatment. Perit Dial Int. 2016;36:481-508.

22. Ivarsen P, Povlsen JV. Can peritoneal dialysis be applied for unplanned initiation of chronic dialysis? Nephrol Dial Transplant. 2014;29:2201-6.

23. Cullis B, Abdelraheem M, Abrahams G, Balbi A, Cruz DN, Frishberg Y, et al. Peritoneal dialysis for acute kidney injury. Perit Dial Int. 2014;34:494-517.

24. Alkatheeri AM, Blake PG, Gray D, Jain AK. Success of urgent-start peritoneal dialysis in a large Canadian renal program. Perit Dial Int. 2016;36:171-6.

25. Cho S, Lee YJ, Kim SR. Acute peritoneal Dialysis in patients with acute kidney injury. Perit Dial Int. 2017;37:529-34.

26. Davies S, Lally F, Satchithananda D, Kadam U, Roffe C. Extending the role of peritoneal dialysis: can we win hearts and minds? Nephrol Dial Transplant. 2014;29:1648-54.

27. Bertoli SV, Musetti C, Ciurlino D, Basile C, Galli E, Gambaro G, et al. Peritoneal ultrafiltration in refractory heart failure: a cohort study. Perit Dial Int. 2014;34: 64-70.

28. KDIGO Group. KDIGO clinical practice guideline for acute kidney injury. Kidney Int Suppl. 2012;2:1-115.

29. Courivaud C, Kazory A, Crépin T, Azar R, Bresson-Vautrin C, Chalopin JM, et al. Peritoneal dialysis reduces the number of hospitalization days in heart failure patients refractory to diuretics. Perit Dial Int. 2014;34:100-8.

30. Kim H, An JN, Kim DK, Kim MH, Kim H, Kim YL, et al. Elderly peritoneal Dialysis compared with elderly hemodialysis patients and younger peritoneal Dialysis patients: competing risk analysis of a Korean prospective cohort study. PLoS One. 2015;10:e0131393.

31. Ghaffari A, Kumar V, Guest S. Infrastructure requirements for an urgent-start peritoneal Dialysis program. Perit Dial Int. 2013;33:611-7.

32. Medani S, Hussein W, Shantier M, Flynn R, Wall C, Mellotte G. Comparison of percutaneous and open surgical techniques for first-time peritoneal Dialysis catheter placement in the Unbreached peritoneum. Perit Dial Int. 2015;35: 576-85.

33. Ozener C, Bihorac A, Akoglu E. Technical survival of CAPD catheters: comparison between percutaneous and conventional surgical placement techniques. Nephrol Dial Transplant. 2001;16:1893-9.

34. Al-Hwiesh AK. Percutaneous peritoneal dialysis catheter insertion by a nephrologist: a new, simple, and safe technique. Perit Dial Int. 2014;34:20411.

35. Atapour A, Asadabadi HR, Karimi S, Eslami A, Beigi AA. Comparing the outcomes of open surgical procedure and percutaneously peritoneal dialysis catheter (PDC) insertion using laparoscopic needle: a two month follow-up study. J Res Med Sci. 2011;16:463-8.

36. Boujelbane L, Fu N, Chapla K, Melnick D, Redfield RR, Waheed S, et al. Percutaneous versus surgical insertion of PD catheters in dialysis patients: a meta-analysis. J Vasc Access. 2015;16:498-505.

37. Tullavardhana T, Akranurakkul P, Ungkitphaiboon W, Songtish D. Surgical versus percutaneous techniques for peritoneal dialysis catheter placement: a meta-analysis of the outcomes. Ann Med Surg (Lond). 2016;10:11-8. 
38. Allon M, Soucie JM, Macon EJ. Complications with permanent peritonea dialysis catheters: experience with 154 percutaneously placed catheters. Nephron. 1988;48:8-11.

39. Moreiras Plaza M, Cuíña L, Goyanes GR, Sobrado JA, Gonzalez L. Mechanical complications in chronic peritoneal dialysis. Clin Nephrol. 1999;52:124-30.

40. Katyal A, Mahale A, Khanna R. Antibiotic prophylaxis before peritoneal dialysis catheter insertion. Adv Perit Dial. 2002;18:112-5.

41. Zappacosta AR, Perras ST, Closkey GM. Seldinger technique for Tenckhoff catheter placement. ASAIO Trans. 1991;37:13-5.

42. Smith SA, Morgan SH, Eastwood JB. Routine percutaneous insertion of permanent peritoneal dialysis catheters on the nephrology ward. Perit Dial Int. 1994;14:284-6.

43. Asif A, Pflederer TA, Vieira CF, Diego J, Roth D, Agarwal A. Does catheter insertion by nephrologists improve peritoneal dialysis utilization? A multicenter analysis. Semin Dial. 2005:18:157-60.

44. Perl J, Pierratos A, Kandasamy G, McCormick BB, Quinn RR, Jain AK, et al. Peritoneal dialysis catheter implantation by nephrologists is associated with higher rates of peritoneal dialysis utilization: a population-based study. Nephrol Dial Transplant. 2015;30:301-9.

45. McDonald SP, Collins JF, Johnson DW. Obesity is associated with worse peritoneal dialysis outcomes in the Australia and New Zealand patient populations. J Am Soc Nephrol. 2003:14:2894-901.

46. Ahmadi SF, Zahmatkesh G, Streja E, Mehrotra R, Rhee CM, Kovesdy CP, et al. Association of Body Mass Index with Mortality in peritoneal Dialysis patients: a systematic review and meta-analysis. Perit Dial Int. 2016;36:315-25.

47. Snyder JJ, Foley RN, Gilbertson DT, Vonesh EF, Collins AJ. Body size and outcomes on peritoneal dialysis in the United States. Kidney Int. 2003;64: 1838-44.

48. Aslam N, Bernardini J, Fried L, Piraino B. Large body mass index does not predict short-term survival in peritoneal dialysis patients. Perit Dial Int. 2002; 22:191-6.

49. Kim YK, Kim SH, Kim HW, Kim YO, Jin DC. The association between body mass index and mortality on peritoneal dialysis: a prospective cohort study. Perit Dial Int. 2014;34:383-9.

50. Singh N, Davidson I, Minhajuddin A, Gieser S, Nurenberg M, Saxena R. Risk factors associated with peritoneal dialysis catheter survival: a 9-year singlecenter study in 315 patients. J Vasc Access. 2010:11:316-22.

51. Krezalek MA, Bonamici N, Kuchta K, Lapin B, Carbray J, Denham W, et al. Peritoneal dialysis catheter function and survival are not adversely affected by obesity regardless of the operative technique used. Surg Endosc. 2018; 32:1714-23.

52. Shanmugalingam R, Makris A, Hassan HC, Li Y, DeGuzman I, Nandakoban H, et al. The utility of Sonographic assessment in selecting patients for percutaneous insertion of peritoneal Dialysis catheter. Perit Dial Int. 2017;37: 434-42.

\section{Publisher's Note}

Springer Nature remains neutral with regard to jurisdictional claims in published maps and institutional affiliations.

Ready to submit your research? Choose BMC and benefit from:

- fast, convenient online submission

- thorough peer review by experienced researchers in your field

- rapid publication on acceptance

- support for research data, including large and complex data types

- gold Open Access which fosters wider collaboration and increased citations

- maximum visibility for your research: over $100 \mathrm{M}$ website views per year

At $\mathrm{BMC}$, research is always in progress.

Learn more biomedcentral.com/submissions 